ВОЗМОЖНОСТИ ИСПОЛЬЗОВАНИЯ ВЫСОКОЭФФЕКТИВНОЙ ЖИДКОСТНОЙ ХРОМАТОГРАФИИ В СОЧЕТАНИИ С ТАНДЕМНОЙ МАСС-СПЕКТРОМЕТРИЕЙ ДЛЯ КОЛИЧЕСТВЕННОГО И КАЧЕСТВЕННОГО ОПРЕДЕЛЕНИЯ БИОЛОГИЧЕСКИ АКТИВНЫХ ВЕЩЕСТВ ЖЕНЫШЕНЯ В ФИТОЭКСТРАКТАХ

\author{
Р.В. Карпова ${ }^{1}$, В.Е. Шевченко ${ }^{1}$, Е.В. Бочаров ${ }^{1}$, О.П. Шейченко ${ }^{2}$, \\ О.А. Бочарова ${ }^{1}$, В.Г. Кучеряну루 ${ }^{3}$ В.А. Быков² \\ ${ }^{\prime}$ ФГБУ «Российский онкологический научный центр им. Н.Н. Блохина» Минздрава России, \\ Россия, 115478, г. Москва, Каширское шоссе, 24; \\ ${ }^{2}$ ФГБНУ «Всероссийский научно-исследовательский институт лекарственных и ароматических растений», Россия, \\ 117216, г. Москва, ул. Грина, 7/1; \\ ${ }^{3}$ ФГБУ «Научно-исследовательский институт общей патологии и патофизиологии» РАМН, \\ Россия, 125315, Москва, ул. Балтийская, 8
}

Контакты: Карпова Регина Васильевна planta39@rambler.ru

Статья посвящена идентификации и количественному определению гинзенозидов в составе мультифитоадаптогенного препарата «Фитомикс-40» (ФМ-40) с компонентами 40 растительных экстрактов, включая женьшень. Препарат обладает широким спектром действия, в том числе антимутагенным, противоопухолевым, радио- и нейропротекторным, иммунои гормономодулирующим, антиоксидантным эффектами.

Цель исследования - определение состава гинзенозидов и их количественного содержания в ФМ-40 с использованием высокоэффективной жидкостной хроматографии в сочетании с тандемной масс-спектрометрией (ВЭЖX-MC/MC).

Материалы и методы. В работе исследовали ФМ-40, препарат сравнения, содержащий компоненты тех же экстрактов растений, что и ФМ-40, только в иных (известных) соотношениях, а также экстракт женьшеня. Для определения отдельных гинзенозидов применяли коммерческие стандарты, а такжее данные литературы. Хроматограммы были получены в коротком (с достижением удовлетворительного разделения веществ) и длинном (более информативном) градиентах подачи мобильной фазы.

Результаты. ВЭЖХ-МС/МС с использованием стандартов гинзенозидов и данных литературы была успешно применена для идентификации и количественного определения гинзенозидов. Установлены оптимальные условия их разделения. Полученные в ходе данных исследований хроматограммы и спектры компонентов препарата могут быть использованы в качестве стандартов гинзенозидов. В составе ФМ-40 выявлены гинзенозиды $R b_{1}, R b_{2}, R c, R d, R g_{1}, R g_{2}, R e, R f, R o, M a л о-$ нил $-R b_{1},-R b_{2} / R b_{3} / R c u-R d$.

Ключевые слова: фитоадаптоген, гинзенозиды, электрораспыление, тандемная масс-спектрометрия, пределы детектирования

DOI: $10.17650 / 1726-9784-2016-15-2-36-46$

\title{
GINSENOSIDES DEFINITION IN PLANT EXTRACTS BY MEANS OF HIGH THROUGH LIQUID CHROMATOGRAPHY WITH TANDEM MASS-SPECTROMETRY
}

R.V. Karpova', V.E. Shevchenko ${ }^{1}$, E.V. Bocharov ${ }^{1}$, O.P. Sheychenko ${ }^{2}$, O.A. Bocharova ${ }^{1}$, V.G. Kucheryanu ${ }^{3}$, V.A. Bykov ${ }^{2}$

${ }^{1}$ N.N. Blokhin Russian Cancer Research Center, Ministry of Health of Russia; 24 Kashirskoe Shosse, Moscow, 115478, Russia

${ }^{2}$ All-Russian Research Institute of Medical and Aromatic plants, 7/1 Green St, Moscow, 117216, Russia

${ }^{3}$ Institute of general pathology and pathophysiology, 8 Baltiyskaya St, Moscow, 125315, Russia

Background. Present study was dedicated to identification and evaluation of the biologically active components in multiphytoadaptogene preparation phytomix-40 (PhM-40). It consists of forty plant extracts components including Panax ginseng. PhM-40 demonstrates wide spectrum of biological effects including antimutagenic, antitumor, radioprotective, hormone-modulating, antioxidant, neuroprotective and ummunomodulating activities. Objective: of this study was to identify and to quantify ginsenosides content in the preparation. Materials and method. Experimental design included the comparison of ginsenosides content evaluation in PhM-40, comparison preparation (which contains similar to PhM-40 plant extracts components but another rations) and Panax ginseng extract by means 
of LC-MS/MS spectroscopy method. Two different gradients were used: the short and the long ones. By means of the short one rapid compound identification with economical consumption of chemicals was possible as well as the long one allowed us to identify compounds with better resolution capability. Commercially available ginsenosides were the standards for calibration. Literature data were also used for ginsenosides identification.

Results. High through liquid chromatography method with tandem mass-spectrometry was successfully used for ginsenosides identification quantitatively and qualitatively in plant preparation PhM-40. The data obtained show the ginsenosides qualitative composition which has been identified as $R b_{1}, R b_{2}, R c, R d, R g_{1}, R g_{2}, R e, R f, R o$, malonyl-R $b_{1},-R b_{2} / R b_{3} / R c$, $-R d$ enumeration in $\mathrm{PhM}-40$

Key words: phytoadaptogene, ginsenosides, electro spray, tandem mass-spectrometry, limits of detection.

\section{Введенше}

В РОНЦ им. Н.Н. Блохина разработан мультифитоадаптогенный препарат «Фитомикс-40» (ФМ-40) с целью профилактики и комплексного лечения онкологических заболеваний в частности и возрастных патологий в общем [1, 2]. Препарат исследован на экспериментальных моделях и в клинике. Выявлено антимутагенное, противоопухолевое, радио-и нейропротекторное, антиоксидантное, гормоно- и иммуномодулирующее (в том числе противовоспалительное и интерфероногенное) действие ФМ-40 [3-12]. При клиническом изучении ФМ-40 был доказан лечебный эффект в отношении доброкачественной гиперплазии предстательной железы (возрастное заболевание), лейкоплакии слизистой оболочки полости рта (предрак), распространенного рака желудка (IV стадия развития) и болезни Паркинсона (возрастное нейродегенеративное заболевание) [13-18]. Полученные в рамках проведенных исследований данные свидетельствуют об эффективности ФМ-40, которая, вероятно, обусловлена комплексом биологически активных веществ 40 растительных экстрактов, входящих в его состав [19-24], из них компоненты экстракта женьшеня являются одними из важнейших.

В ранее проведенных исследованиях с использованием спектроскопии ядерного магнитного резонанса были установлены характеристики компонентов экстрактов растений мультифитоадаптогена ФМ-40, а также количественно определены действующие вещества в одномерных спектрах методом внутреннего стандарта [25]. Установлен состав летучих веществ препарата при использовании хромато-масс-спектрометрии [26].

Применение обращенно-фазовой высокоэффективной жидкостной хроматографии с УФ-детектором при использовании стандартных образцов в составе мультифитоадаптогена ФМ-40 позволило определить наличие полифенольных соединений и аминокислот. В результате обнаружены 8 веществ фенольной природы: гиперозид, рутин, нарингенин, кверцетин, лютеолин, апигенин (флавоноиды), арбутин (фенологликозид) и глицирризиновая кислота (тритерпеновый сапонин). Кроме того, выявлены 18 аминокислот, из них
7 незаменимых [27]. Подход к идентификации и количественной оценке растительных компонентов комплексных фитопрепаратов с применением высокоэффективной жидкостной хроматографии в сочетании с тандемной масс-спектрометрией (ВЭЖХ$\mathrm{MC} / \mathrm{MC}$ ) имеет научно-практическое значение.

Целью данного исследования является определение состава гинзенозидов и их количественного содержания в ФМ-40 при использовании ВЭЖХ-МС/МС.

\section{Mamepuалы u методы}

ФМ-40 представляет собой комплексный препарат на основе компонентов экстрактов 40 растений, в том числе женьшеня, включенных в Государственную фармакопею РФ. Препарат сравнения (ПС) содержит компоненты тех же экстрактов растений, что и ФМ-40, только в иных (известных) соотношениях.

Анализ комплексных препаратов (ФМ-40 и ПС) и отдельно экстракта женьшеня (полученного аналогичным способом) проводили с использованием тройного квадрупольного масс-спектрометра TSQ Vantage серии Thermo Scientific TSQ, соединенного с ВЭЖХ-хроматографом Accela («Thermo Scientific», США), снабженного колонкой ACQUITY UPLC ВЕН С18 (1,7 мкм, 2,1 × 100 мм, производства компании «Waters», США).

В работе использовали стандарты гинзенозидов $\mathrm{Rb}_{1}, \mathrm{Rb}_{2}, \mathrm{Rc}, \mathrm{Rd}, \mathrm{Rg}_{1}, \mathrm{Rh}_{1}$ и $\mathrm{Rh}_{2}$ (ChromaDex), стандарт ланатозид C (в качестве внутреннего стандарта), а также метанол (“Sigma-Aldrich”, США) и ацетонитрил (“Reiden-deHaen”, Германия) для ВЭЖХ.

Для приготовления рабочих растворов стандарты гинзенозидов $\mathrm{Rb}_{1}, \mathrm{Rb}_{2}, \mathrm{Rc}, \mathrm{Rd}, \mathrm{Rg}_{1}, \mathrm{Rh}_{1}$ и $\mathrm{Rh}_{2}$ растворяли в метаноле с конечной концентрацией 1,0 мг/мл. Из каждого рабочего раствора отбирали по 100 мкл и переносили в чистую пробирку, затем доводили метанолом до объема 1 мл. Таким образом получали раствор смеси стандартов с концентрацией каждого 0,1 мг/мл.

Калибровочные растворы готовили на основе метанола с концентрациями 3,$3 ; 5 ; 10 ; 12,5 ; 16,7 ; 20$; $25 ; 50 ; 100 ; 125 ; 166,7 ; 200 ; 250$ и 500 мкг/мл. Каждый образец содержал 2 мкг внутреннего стандарта (ланатозид С). Калибровочные кривые построены в коор- 
динатах: «отношение площади пика стандарта к площади пика внутреннего стандарта - концентрация стандарта».

Образец экстракта женьшеня разводили метанолом в 100 раз, после чего пропускали через фильтр с диаметром пор 0,22 мкм.

Образцы фитомикстур смешивали с метанолом в соотношении 1:2 и центрифугировали 5 мин при 13000 об/мин. Надосадочную жидкость пропускали через фильтр с диаметром пор 0,22 мкм и центрифугировали 1 мин при 13000 об/мин.

Условия хроматографирования:

- фаза А: $100 \%$ вода и 0,1 \% муравьиная кислота (FA);

- фаза В: 95 \% ацетонитрил, 5 \% вода и 0,1 \% FA.

Для анализа стандартов гинзенозидов, экстракта женьшеня и препаратов ФМ-40 и ПС использовали 2 градиента:

1) «короткий»: 0-15 мин (21-60\% фазы В), 1518 мин (60-100\% В), 18-25 мин (100\% В), 25-33 мин (21\% В);

2) «длинный»: 0-68 мин (0-60\% фазы В), 68-70 мин (60-100 \% В), 70-75 мин (100\% В), 75-80 мин (0\% B).

Объем вводимой пробы составлял 5 мкл при объеме петли 25 мкл, скорость потока - 450 мкл/мин.

Ионизацию осуществляли с помощью электроспрея. Условия ионизации: отрицательная полярность, напряжение капилляра электроспрея - 4 кВ, газ (создающий спрей $)-60$ psi $(1$ psi $=6894,757$ Па), обтекающий газ - 15 отн. ед., температура капилляра $-270{ }^{\circ} \mathrm{C}$. Спектры в режиме полного сканирования и режиме сканирования отдельных ионов были сняты в диапазоне 150-1500 Да, время сканирования $-0,1 \mathrm{c}$.

MC/MC-спектры стандартов и соединений в экстракте получали прямым вводом пробы через шприц со скоростью 5 мкл/мин; давление газа в камере соударений $-0,9$ мТорр ${ }^{1}$. Напряжение в камере соударений было подобрано для каждого соединения отдельно.

Для количественного определения гинзенозидов в режиме детектирования отдельных ионов были проанализированы образцы смеси стандартов, экстракта женьшеня, а также препаратов ФМ-40 и ПС.

Для качественного и количественного определения основных компонентов женьшеня в составе фитопрепаратов с использованием стандартов гинзенозидов были сняты отдельные хроматограммы смеси стандартов гинзенозидов, экстракта женьшеня, входящего в составы фитокомпозиций, а также самих препаратов ФМ-40 и ПС. Все перечисленные хроматограммы были получены в коротком (более экономном) и длинном (более информативном) градиентах подачи мобильной фазы. Для построения калибровочной кривой, необходимой для количественного определения гинзенозидов в препаратах, нужно было получить хроматограммы стандартов гинзенозидов в большом диапазоне концентраций. Для экономии реактивов и времени использован максимально короткий градиент подачи растворителя, при котором достигалось удовлетворительное разделение веществ (рис. 1), при этом экстракт женьшеня и фитопрепараты также были сняты в этих же условиях (см. рис. 2 и $3, a$ на с. 40 , рис. 4 и $5, a$ на с. 41 ). Хроматограммы экстракта женьшеня, ФМ-40 и ПС с длинным градиентом (как более информативные) получены для анализа по данным литературы тех гинзенозидов, стандартов которых у нас не было.

\section{Результаты и обсуждение}

Хроматограмма полного ионного тока смеси стандартов гинзенозидов $\mathrm{Rg}_{1}, \mathrm{Rb}_{1}, \mathrm{Rh}_{1}, \mathrm{Rc}, \mathrm{Rb}_{2}, \mathrm{Rd}$ и $\mathrm{Rh}_{2}$ (в соответствии с очередностью выхода) представлена на рис. 1. В табл. 1 для каждого гинзенозида приведены молекулярная масса (MM), структурная формула, время удерживания $\left(\mathrm{R}_{\mathrm{t}}\right)$, значения отношения массы иона к его заряду $(\mathrm{m} / \mathrm{z})$ для основного молекулярного иона, а также для фрагментов молекулярного иона, полученных в результате тандемной масс-спектрометрии (данные МС/MC). Как следует из данных табл. 1, при первичной ионизации (в отрицательном режиме) большинство гинзенозидов $\left(\mathrm{Rb}, \mathrm{Rc}, \mathrm{Rb}_{2}, \mathrm{Rd}\right)$ образовывали квазимолекулярные ионы $[\mathrm{M}-\mathrm{H}]^{-}$, а некоторые из них (с меньшей молекулярной массой, такие как $\mathrm{Rg}_{1}, \mathrm{Rh}_{1}$ и $\mathrm{Rh}_{2}$ ) - ионы-аддукты $[\mathrm{M}+\mathrm{FA}-\mathrm{H}]^{-}$c FA, входящей в состав мобильной фазы.

Полученные данные МC/MC (при вторичной ионизации и фрагментации молекулярных ионов) хорошо согласуются со структурными формулами гинзенозидов. Результаты анализа фрагментов ионов и сопоставление их со структурной формулой для каждого гинзенозида также приведены в табл. 1.

Фрагменты гинзенозидов образуются в основном за счет последовательного отщепления молекул сахаров (глюкозы, арабинозы). Конечные фрагменты соответствуют агликонам 20 (S) - протопанаксадиолу (для гинзенозидов $\mathrm{Rb}_{1}, \mathrm{Rb}_{2}, \mathrm{Rc}_{2} \mathrm{Rh}_{2}$ ) и $20(\mathrm{~S})$ - протопанаксатриолу (для гинзенозидов $\mathrm{Rg}_{1}, \mathrm{Rg}_{2}, \mathrm{Rh}_{1}$ ).

Хроматограмма полного ионного тока экстракта женьшеня получена с использованием короткого градиента подачи растворителей (рис. 2). Она содержит не менее 12 пиков, которые можно отнести к гинзе-

${ }^{1} 1$ Торр $=1$ мм рт. ст. $=133,322$ Па. 


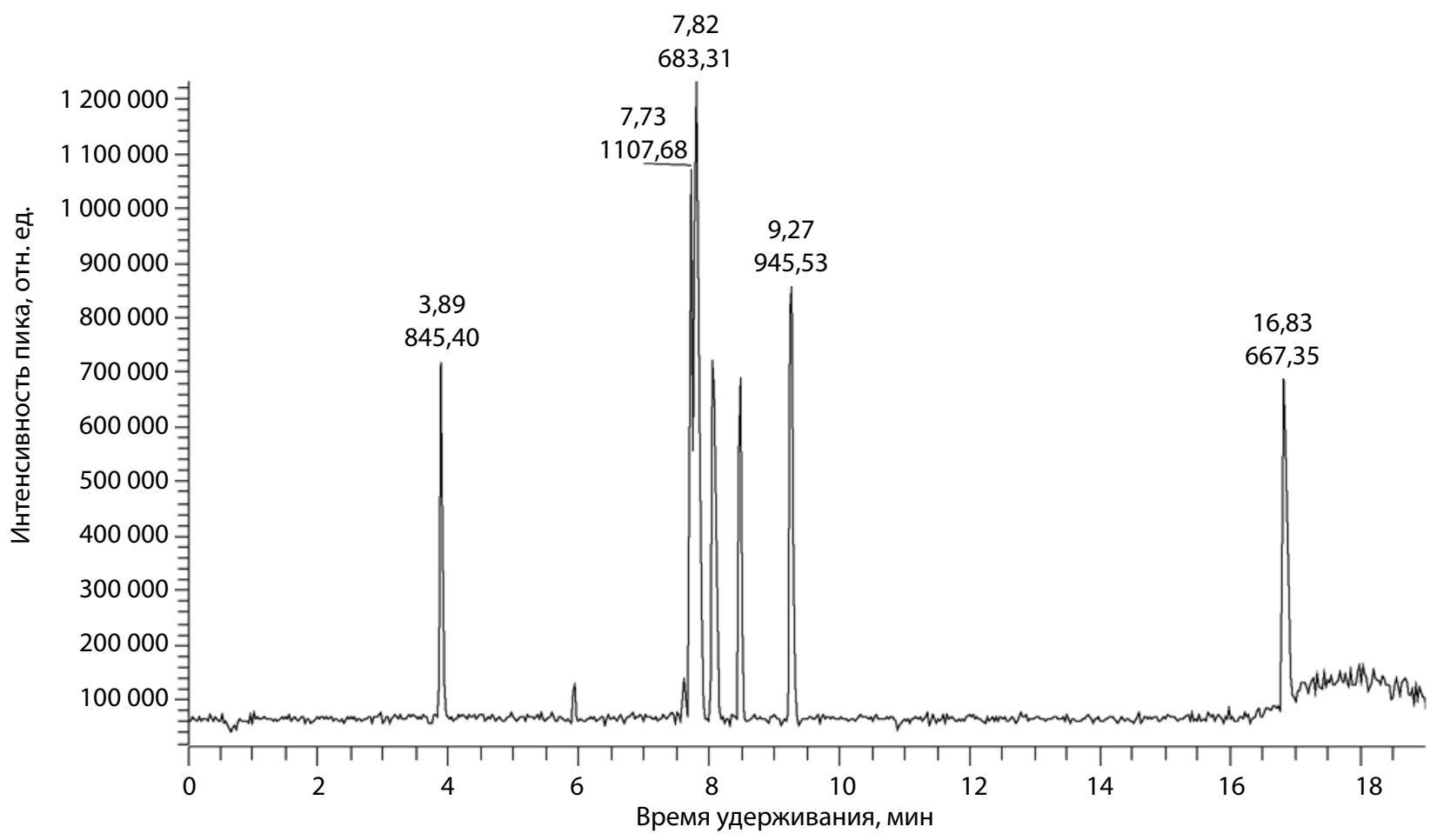

Рис. 1. Хроматограмма полного ионного тока смеси стандартов гинзенозидов

нозидам. Пик со временем удерживания $\mathrm{R}_{\mathrm{t}}=6$ мин соответствует внутреннему стандарту ланатозид C. В экстракте женьшеня при сопоставлении времени удерживания и масс-спектров со стандартами гинзенозидов были идентифицированы следующие гинзенозиды: $\mathrm{Rg}_{1}, \mathrm{Rc}, \mathrm{Rb}_{1}, \mathrm{Rb}_{2}, \mathrm{Rd}$ (пики 1, 4, 6, 8 и 11 соответственно). Гинзенозиды $\mathrm{Rh}_{1}$ и $\mathrm{Rh}_{2}$ не были выявлены.

Хроматограммы полного ионного тока препаратов ФМ-40 и ПС сняты в режиме полного сканирования ионов (рис. 3 и 4). Для обнаружения гинзенозидов хроматограммы ФМ-40 и ПС сняты в режиме сканирования отдельных ионов, массы которых соответствовали массам молекулярных ионов гинзенозидов:
a) $845-846\left(\mathrm{Rg}_{1}\right)$,
б) $945-946(\mathrm{Rd})$,
в) $1077-1078\left(\mathrm{Rc}\right.$ и $\left.\mathrm{Rb}_{2}\right)$,
г) 1107-1108 $\left(\mathrm{Rb}_{1}\right)$.

B качестве иллюстрации на рис. 5 приведена хроматограмма препарата ФМ-40, снятая в режиме сканирования указанных ионов [28-31].

В результате сопоставления времени удерживания и масс-спектров со стандартами гинзенозидов в составе ФМ-40 и ПС были идентифицированы гинзенозиды $\mathrm{Rg}_{1}, \mathrm{Rc}, \mathrm{Rb}_{1}, \mathrm{Rb}_{2}, \mathrm{Rd}$, такие же, как и в экстракте женьшеня. При этом сравнивая хроматограммы препаратов (рис. 3 и 4), легко заметить, что в ФМ-40 уровень гинзенозидов значительно выше, чем в ПС.

Для более точной оценки количественного содержания гинзенозидов в препаратах для каждого гинзенозида построены калибровочные кривые с использованием ланатозида С в качестве внутреннего стандарта.

Из стокового раствора стандартов гинзенозидов приготовлены растворы для калибровки с концентрацией каждого стандарта в диапазоне $3 \div 500$ мкл/мл. В пробы добавляли внутренний стандарт ланатозид C, концентрация которого во всех пробах составляла 1 мкг/мл. По полученным данным для каждого стандарта построена калибровочная кривая в координатах: «отношение площади пика стандарта гинзенозида к площади пика внутреннего стандарта - концентрация стандарта гинзенозида». Как видно в табл. 2, коэффициент корреляции $(r)$ для всех полученных калибровочных кривых превышает $0,98(r>0,98)$. Растворы вводили в прибор трижды: в 1-й, 2-й и 5-й дни приготовления раствора смеси стандартов. Образцы хранили при температуре $4{ }^{\circ} \mathrm{C}$. Относительное стандартное отклонение для проб составило $0,5-2,7 \%$ для снятых в один день и 0,4-3,2\% для снятых в разные дни.

Как следует из результатов качественного и количественного анализа гинзенозидов в препаратах ФМ-40 и ПС (табл. 3), в ФМ-40 по сравнению с ПС содержится в 3 раза больше всех установленных гинзенозидов, что согласуется с различиями в составе фитокомпозиций (в ФМ-40 было внесено заведомо в 3 раза больше по объему экстрактов растенийадаптогенов, чем в ПС).

Большой объем научной литературы, посвященной составу экстрактов женьшеня, позволил иденти- 
Таблица 1. Результаты хроматографического исследования гинзенозидов, сопоставление экспериментальных данных $M C / M C$ структурных формул гинзенозидов

\begin{tabular}{|c|c|c|c|c|}
\hline $\begin{array}{c}\text { № } \\
\text { пика }\end{array}$ & $\begin{array}{c}\text { Гинзено- } \\
\text { зид }\end{array}$ & $\begin{array}{c}\text { ММ, } \\
\text { г/моль }\end{array}$ & Rt, мин & Данные МС, m/z \\
\hline 1 & $\begin{array}{c}\mathrm{Cg}_{42} \mathrm{H}_{72} \mathrm{O}_{14}\end{array}$ & 801 & $3,9-4,0$ & $\begin{array}{l}845,5[\mathrm{M}+\mathrm{FA}-\mathrm{H}]^{-} \\
799,5[\mathrm{M}-\mathrm{H}]^{-} \\
637,5\left[\mathrm{M}-\mathrm{H}-\mathrm{Glc}^{-}\right. \\
475,3 \mathrm{Agl} .\end{array}$ \\
\hline 2 & $\mathrm{C}_{54} \mathrm{Hb}_{92}^{\mathrm{Hb}_{1}} \mathrm{O}_{23}$ & 1109,3 & $7,7-8$ & $\begin{array}{l}1107,78[\mathrm{M}-\mathrm{H}]^{-} \\
783,2[\mathrm{M}-\mathrm{H}-2 \mathrm{Glc}]^{-} \\
621,5[\mathrm{M}-\mathrm{H}-3 \mathrm{Glc}]^{-} \\
459,25 \mathrm{Agl} .\end{array}$ \\
\hline 3 & $\underset{\mathrm{C}_{36}}{\mathrm{Rh}_{62}}{ }_{6} \mathrm{O}_{9}$ & 639 & $7,8-7,9$ & $\begin{array}{l}\text { 683,35[M + FA }-\mathrm{H}]^{-} \\
637,4[\mathrm{M}-\mathrm{H}]^{-} \\
\text {475,2 Agl. }\end{array}$ \\
\hline 4 & $\stackrel{\mathrm{Rc}}{\mathrm{C}_{53}} \stackrel{\mathrm{H}_{90}}{\mathrm{O}_{22}}$ & 1079,3 & $8,1-8,4$ & $\begin{array}{l}\text { 1077,62 [M - H }]^{-} \\
945,6\left[\mathrm{M}-\mathrm{H}-\mathrm{Araf}^{-}\right. \\
783,2[\mathrm{M}-\mathrm{H}-\mathrm{Araf}-\mathrm{Glc}]^{-} \\
621,3[\mathrm{M}-\mathrm{H}-\mathrm{Araf}- \\
2 \mathrm{Glc}]^{-} \\
455,2 \mathrm{Agl} .\end{array}$ \\
\hline 5 & $\mathrm{C}_{53} \mathrm{Rb}_{90}^{\mathrm{Rb}_{2}} \mathrm{O}_{22}$ & 1079,3 & $8,5-8,8$ & $\begin{array}{l}\text { 1077,62 [M - H }]^{-} \\
945,6\left[\mathrm{M}-\mathrm{H}-\text { Arap }^{-}\right. \\
783,2\left[\mathrm{M}-\mathrm{H}-{\text { Arap }-\mathrm{Glc}]^{-}}_{621,3[\mathrm{M}-\mathrm{H}-\text { Arap }-}\right. \\
2 \mathrm{Glc}]^{-} \\
\text {455,2 Agl. }\end{array}$ \\
\hline 6 & $\mathrm{C}_{48} \stackrel{\mathrm{Rd}}{\mathrm{H}_{82}} \mathrm{O}_{18}$ & 947,2 & $9,25-9,6$ & $\begin{array}{l}945,34[\mathrm{M}-\mathrm{H}]^{-} \\
783,19[\mathrm{M}-\mathrm{H}-\mathrm{Glc}]^{-} \\
621,6[\mathrm{M}-\mathrm{H}-2 \mathrm{Glc}]^{-} \\
\text {459,4 Agl. }\end{array}$ \\
\hline 7 & $\underset{\mathrm{C}_{36}}{\mathrm{Rh}_{62}} \mathrm{H}_{8}$ & 623 & $16,8-17$ & $\begin{array}{l}667,43[\mathrm{M}+\mathrm{FA}-\mathrm{H}]^{-} \\
621,49[\mathrm{M}-\mathrm{H}]^{-} \\
\text {459,04 Agl. }\end{array}$ \\
\hline
\end{tabular}

Примечание: $М M-$-молекулярная масса, $R_{t}$ - время удерживания, $M C$ - масс-спектрометрический анализ, Araf - арабиноза (фураноза), Аrap - арабиноза (пираноза), Glc - глюкоза, Agl. - агликон, FA - муравьиная кислота, $m$ - масса иона; $z$ - заряд иона.

фицировать в экстракте не только те гинзенозиды, стандарты которых у нас были [28-34, 35]. Сопоставление полученных нами экспериментальных и литературных данных позволило (на основании результатов MC/MC) с большой долей вероятности идентифицировать в составе экстракта женьшеня гинзенозиды $\mathrm{Re}, \mathrm{Ro}, \mathrm{Rg}_{2}, \mathrm{Rf}$ и др. (табл. 4 и 5) и оценить их присутствие в фитопрепаратах (соответствие массы иона и времени удерживания на хроматограммах экстракта и препарата). Корректность идентификации веществ в экстракте женьшеня на основании данных литературы (табл. 4) подтверждается результатами МC/MC (табл. 5).

Поскольку площадь пика на хроматограмме, полученной с использованием масс-детектора типа ионной ловушки, является величиной, прямо пропорциональной количеству вещества, дающего дан- ный пик, то при сравнении площади соответствующих пиков на хроматограммах ФМ-40 и ПС можно приблизительно оценить содержание интересующих нас веществ в одном препарате относительно другого.

В первую очередь были определены соотношения площадей пиков на хроматограммах ФМ-40 и ПС для гинзенозидов $\mathrm{Rg}_{1}, \mathrm{Rc}, \mathrm{Rb}_{1}, \mathrm{Rb}_{2}, \mathrm{Rd}$, количество и соотношение которых в препаратах было точно установлено по калибровочным кривым с использованием внутреннего стандарта (см. табл. 3). Площади пиков были определены на хроматограммах полного ионного тока препаратов, снятых в режиме полного сканирования ионов с использованием длинного градиента подачи мобильной фазы. Отрезки этих хроматограмм с временными интервалами, соответствующими временам выхода пиков гинзенозидов $\mathrm{Rg}_{1}, \mathrm{Rc}, \mathrm{Rb}_{1}, \mathrm{Rb}_{2}$ и $\mathrm{Rd}$, представлены на рис. 6-7. Полученные результаты приведены в табл. 6 и 7. Как видно, площади пиков на хроматограммах препаратов различаются приблизительно на одинаковую величину, в среднем пики гинзенозидов на хроматограмме ФМ-40 имеют площадь в 1,15 раз бо́льшую, чем на хроматограмме ПС. А поскольку (в соответствии с данными табл. 3) они должны различаться в среднем в 3 раза, правомерно ввести поправочный коэффициент 2,62 (результат деления 3 на 1,15). Тогда содержание гинзенозидов в препарате ФМ-40, установленное как методом количественного определения, так и непосредственным сравнением площадей пиков, получается в 3 раза выше по сравнению с содержанием гинзенозидов в препарате ПС. Следует отметить, что применять этот коэффициент правомерно только для данных конкретных хроматограмм ФМ-40 и ПС, для которых он был рассчитан. Для других хроматограмм нужно будет рассчитывать свой поправочный коэффициент.

Введение поправочного коэффициента может быть оправдано тем обстоятельством, что хроматограммы препаратов ФМ-40 и ПС были получены независимо друг от друга (таким образом, возможны неконтролируемые изменения условий хроматографирования и т. п.). В данном случае эти гинзенозиды выступают в роли внутреннего стандарта, присутствующего в установленном количестве в обоих препаратах, с его помощью можно привести хроматограммы разных образцов к одинаковым универсальным условиям получения (т. е. выровнять условия получения хроматограмм разных образцов).

Таким образом, с использованием стандартов гинзенозидов, помимо прочего, определен поправочный коэффициент, позволяющий через сравнение хроматограмм препаратов количественно оценить различия между ФМ-40 и ПС по содержанию основных биологически активных веществ. 


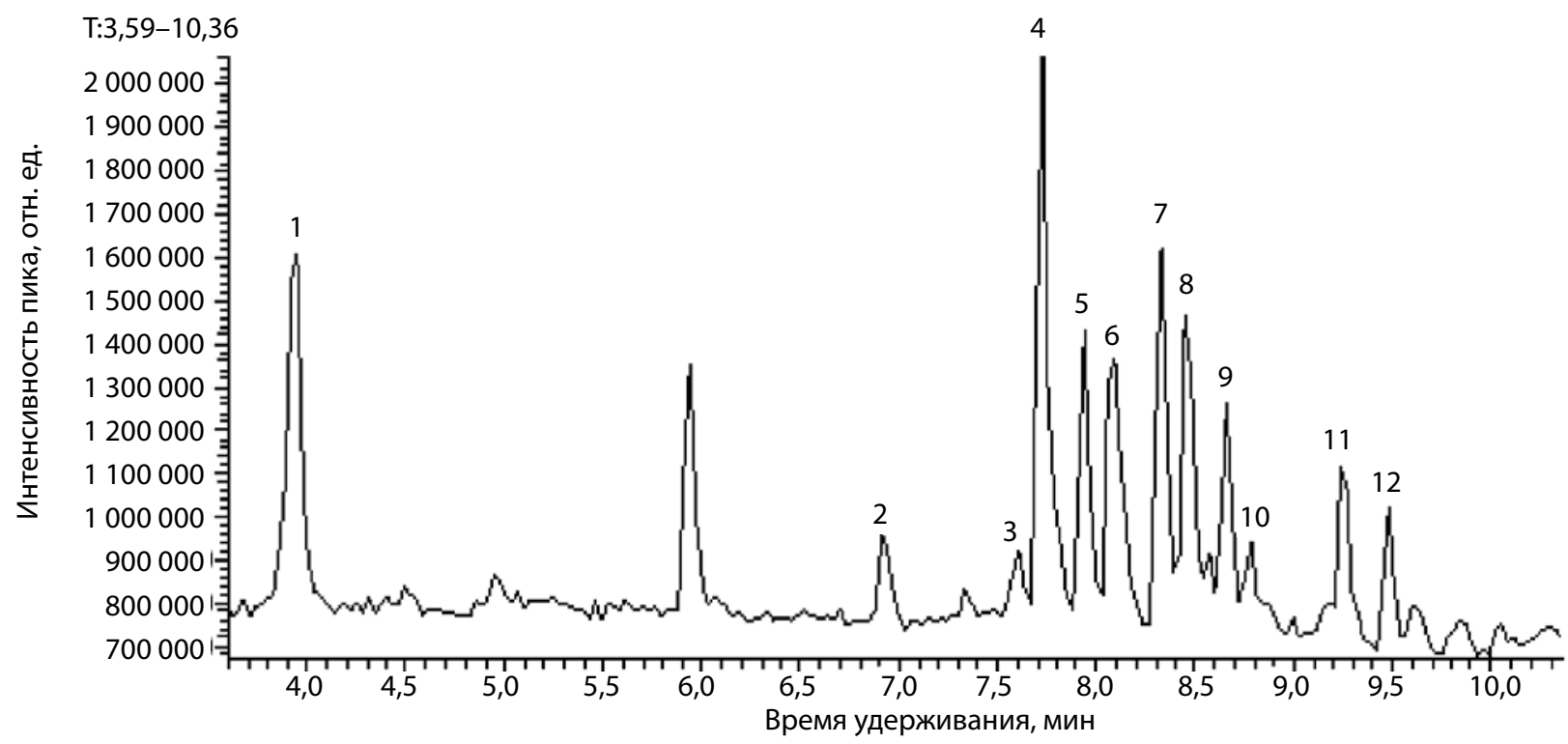

Рис. 2. Хроматограмма полного ионого тока экстракта женьщеня (короткий градиент)
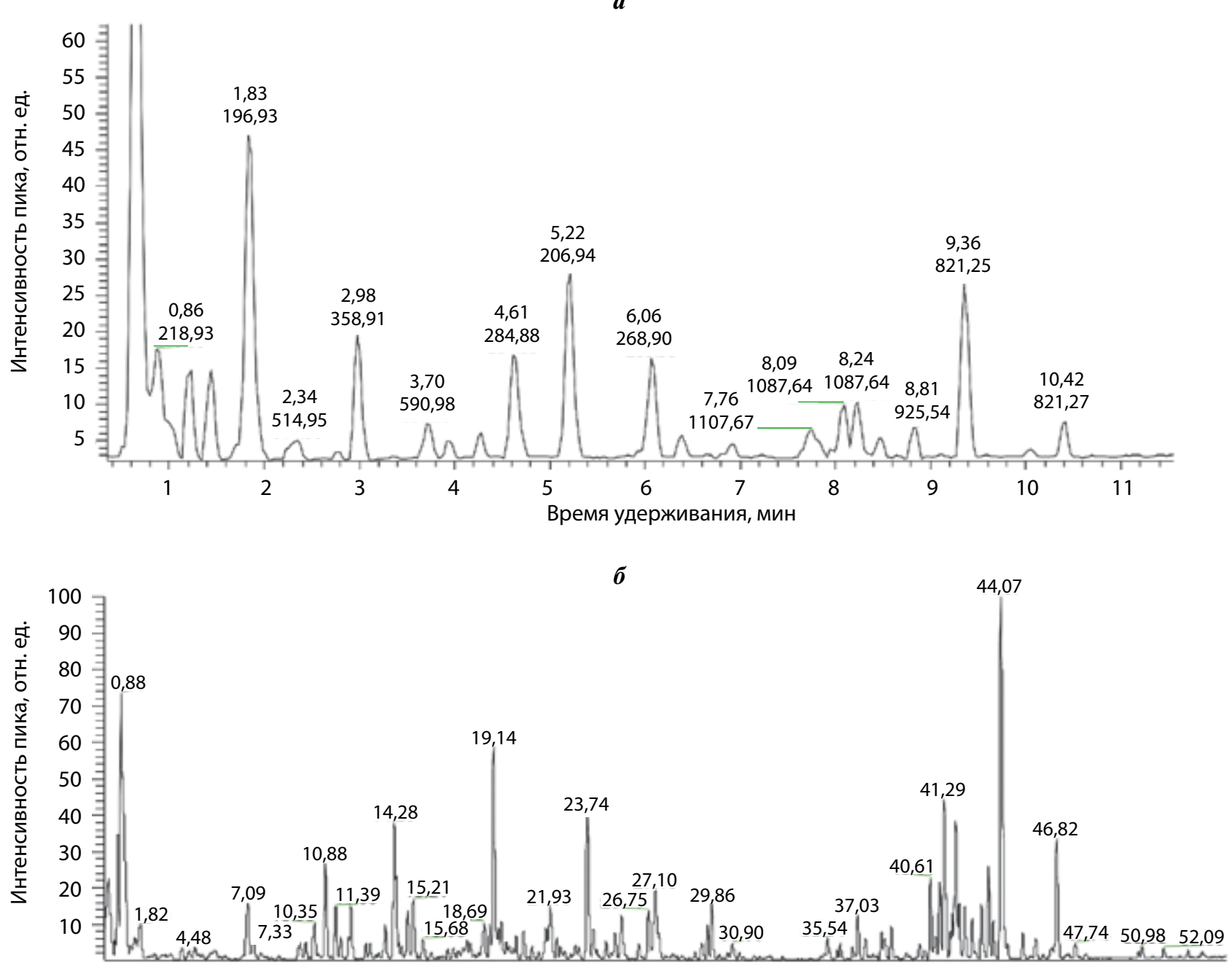

Время удерживания, мин

Рис. 3. Хроматограмма полного ионного тока препарата «Фитомикс-40»: $a$ - короткий градиент; б - длинный градиент 

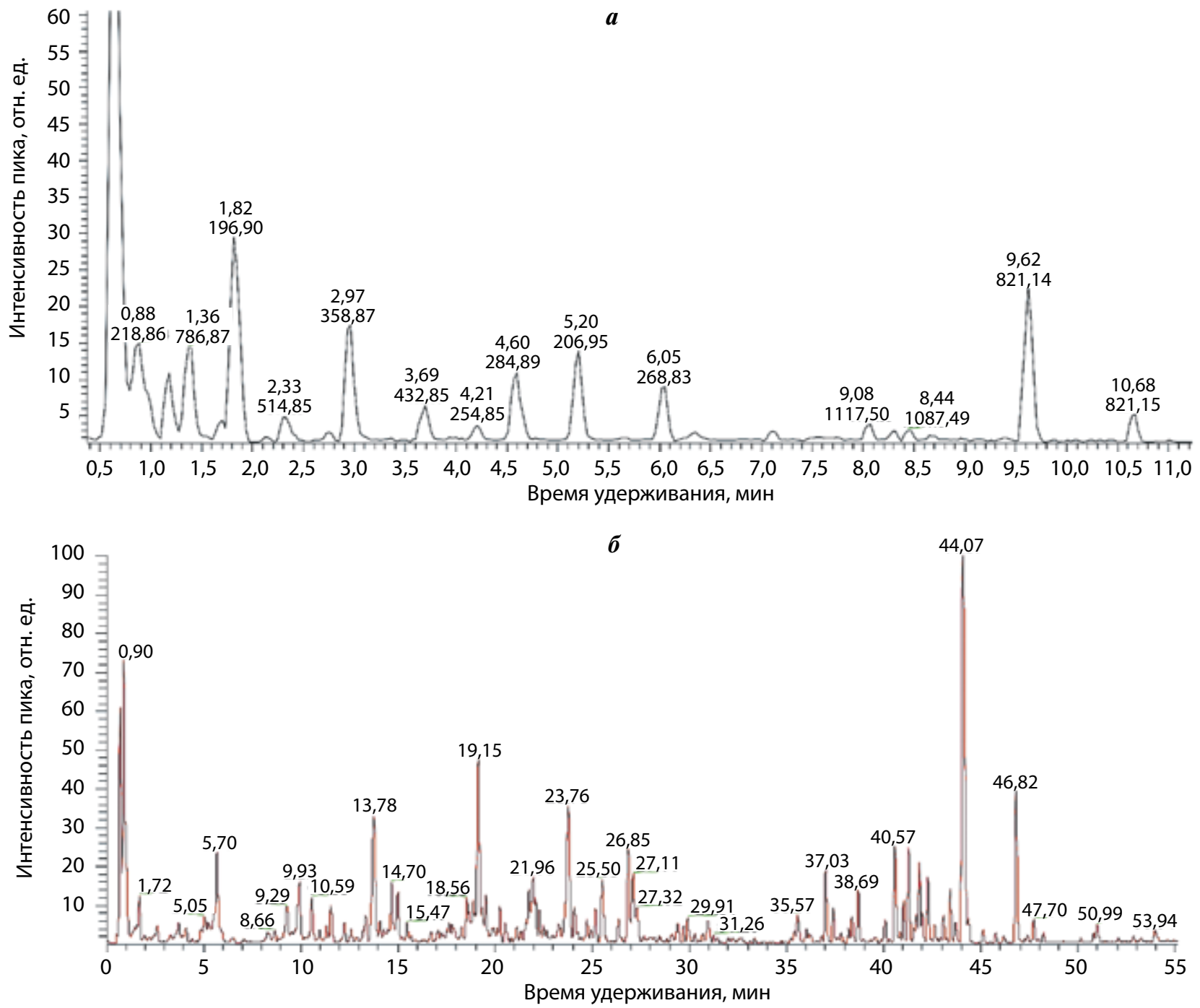

Рис. 4. Хроматограмма полного ионного тока препарата сравнения; $а$ - короткий градиент; б - длинный градиент

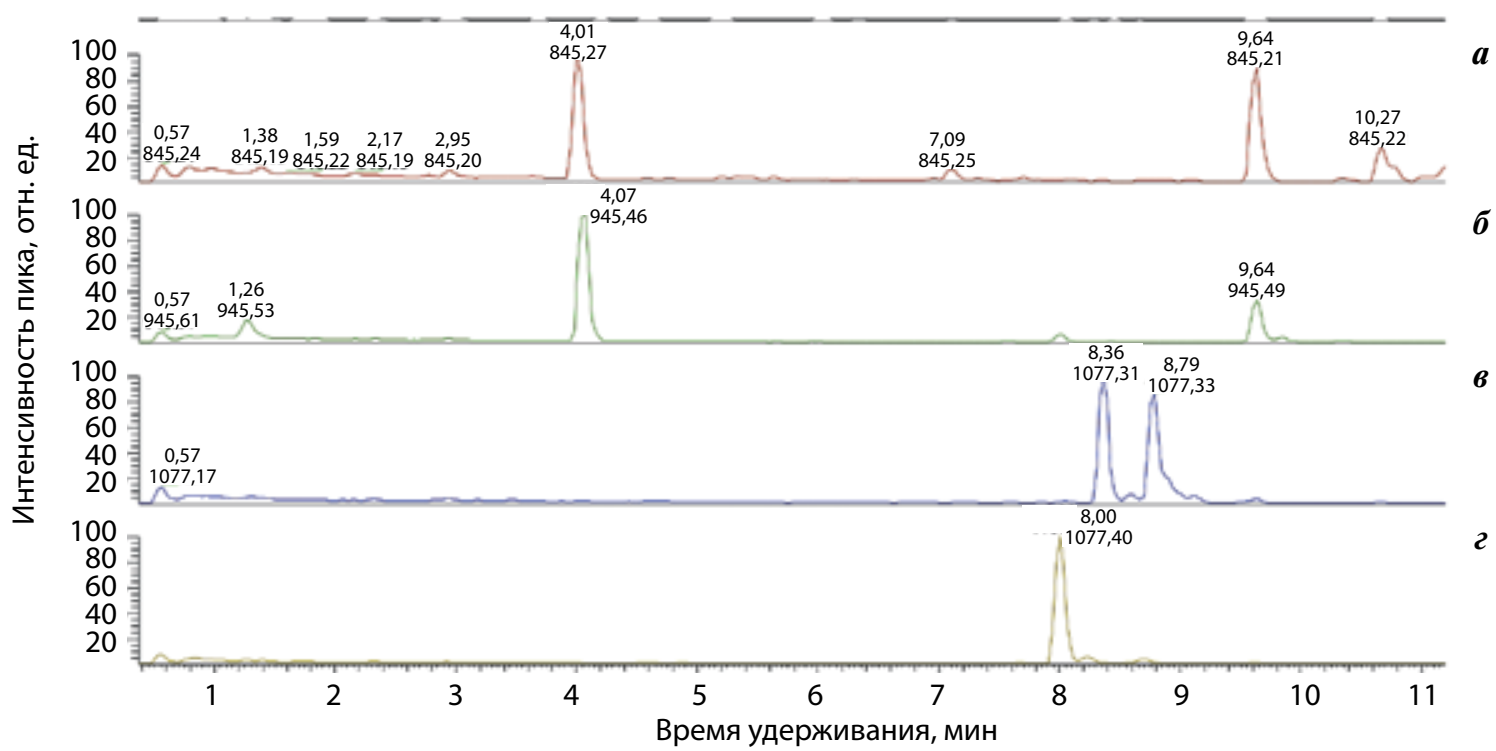

Рис. 5. Хроматограммы препарата «Фитомикс-40» (короткий градиент) в режиме сканирования отдельных ионов массами: 845-846 (а); 945-946 (6); 1077-1078 (8); 1107-1108 (2) 
Таблица 2. Калибровочные кривые и коэффициенты корреляции для стандартов гинзенозидов

\begin{tabular}{|c|c|c|}
\hline Гинзенозид & $\begin{array}{c}\text { Уравнение } \\
\text { калибровочной кривой }\end{array}$ & $\begin{array}{c}\text { Коэффициент } \\
\text { корреляции } \boldsymbol{r}\end{array}$ \\
\hline $\mathrm{Rg}_{1}$ & $\mathrm{y}=0,0122 \mathrm{x}-0,0322$ & 0,9902 \\
\hline $\mathrm{Rb}_{1}$ & $\mathrm{y}=0,0202 \mathrm{x}+0,1484$ & 0,9900 \\
\hline $\mathrm{Rc}$ & $\mathrm{y}=0,0108 \mathrm{x}-0,0112$ & 0,9918 \\
\hline $\mathrm{Rb}$ & $\mathrm{y}=0,0091 \mathrm{x}-0,0255$ & 0,9897 \\
\hline $\mathrm{Rd}$ & $\mathrm{y}=0,0220 \mathrm{x}+0,0985$ & 0,9907 \\
\hline
\end{tabular}

Таблица 3. Качественный и количественный состав гинзенозидов в фumonpenapamax

\begin{tabular}{|c|c|c|c|}
\hline \multirow{2}{*}{ Гинзенозид } & \multicolumn{2}{|c|}{$\begin{array}{c}\text { Содержание гинзенозида, } \\
\text { мкг/мл }\end{array}$} & $\begin{array}{c}\text { Соотношение } \\
\text { гинзенозидов } \\
\text { в ФМ-40 и ПС }\end{array}$ \\
\cline { 2 - 4 } & ФМ-40 & ПС & 2,91 \\
\hline $\mathrm{Rg}_{1}$ & 278,343 & 95,651 & 3,05 \\
\hline $\mathrm{Rb}_{1}$ & 339,801 & 111,410 & 2,99 \\
\hline $\mathrm{Rc}$ & 279,293 & 93,409 & 2,90 \\
\hline $\mathrm{Rb}$ & 432,531 & 149,149 & 3,15 \\
\hline $\mathrm{Rd}$ & 112,462 & 35,702 & \\
\hline
\end{tabular}

Примечание: ФМ-40 - фитомикс-40, ПС - препарат сравнения.
Таблица 4. Определение гинзенозидов в экстракте женьшеня с использованием ВЭЖХ-МС/МС на основании данных литературы (номера пиков соответствуют данным, представленным на рис. 2)

\begin{tabular}{|c|c|c|c|c|c|}
\hline \multirow{2}{*}{$\begin{array}{l}\text { № } \\
\text { пика }\end{array}$} & \multirow{2}{*}{$\begin{array}{l}\mathbf{R}_{t} \text {, } \\
\text { мин }\end{array}$} & \multirow{2}{*}{ Гинзенозид } & \multicolumn{3}{|c|}{ Масса ионов } \\
\hline & & & {$[\mathbf{M}-\mathbf{H}]^{-}$} & {$[\mathbf{M}+\mathbf{F A}-\mathbf{H}]^{-}$} & {$\left[\mathrm{M}-\mathrm{CO}_{2}-\mathrm{H}\right]^{-}$} \\
\hline 1 & 3,95 & $\operatorname{Re}$ & 945 & - & - \\
\hline 2 & 6,91 & $\mathrm{Rf}$ & 799 & 845 & - \\
\hline 4 & 7,79 & $\mathrm{Rg}_{2}$ & 783 & - & - \\
\hline 5 & 7,94 & $\begin{array}{c}\text { Мало- } \\
\text { нил- } \mathrm{Rb}_{1}\end{array}$ & - & - & 1149 \\
\hline 7 & 8,33 & $\begin{array}{l}\text { Малонил- } \\
\mathrm{Rb}_{2} / \mathrm{Rb}_{3} / \mathrm{Rc}\end{array}$ & - & - & 1119 \\
\hline 7 & 8,33 & Ro & 955 & - & - \\
\hline 9 & 8,66 & $\begin{array}{c}\text { Малонил- } \\
\mathrm{Rb}_{2} / \mathrm{Rb}_{3} / \mathrm{Rc}\end{array}$ & - & - & 1119 \\
\hline 10 & 8,78 & $\begin{array}{l}\text { Малонил- } \\
\mathrm{Rb}_{2} / \mathrm{Rb}_{3} / \mathrm{Rc}\end{array}$ & - & - & 1119 \\
\hline 12 & 9,48 & $\begin{array}{l}\text { Мало- } \\
\text { нил-Rd }\end{array}$ & - & - & 987 \\
\hline
\end{tabular}

Примечание: $R_{t}$ - время удерживания, FA - муравьиная кислота.

Расчетное соотношение гинзенозидов, идентифицированных в препаратах на основании данных литературы [28-34, 35], приведено в табл. 7. Из ее

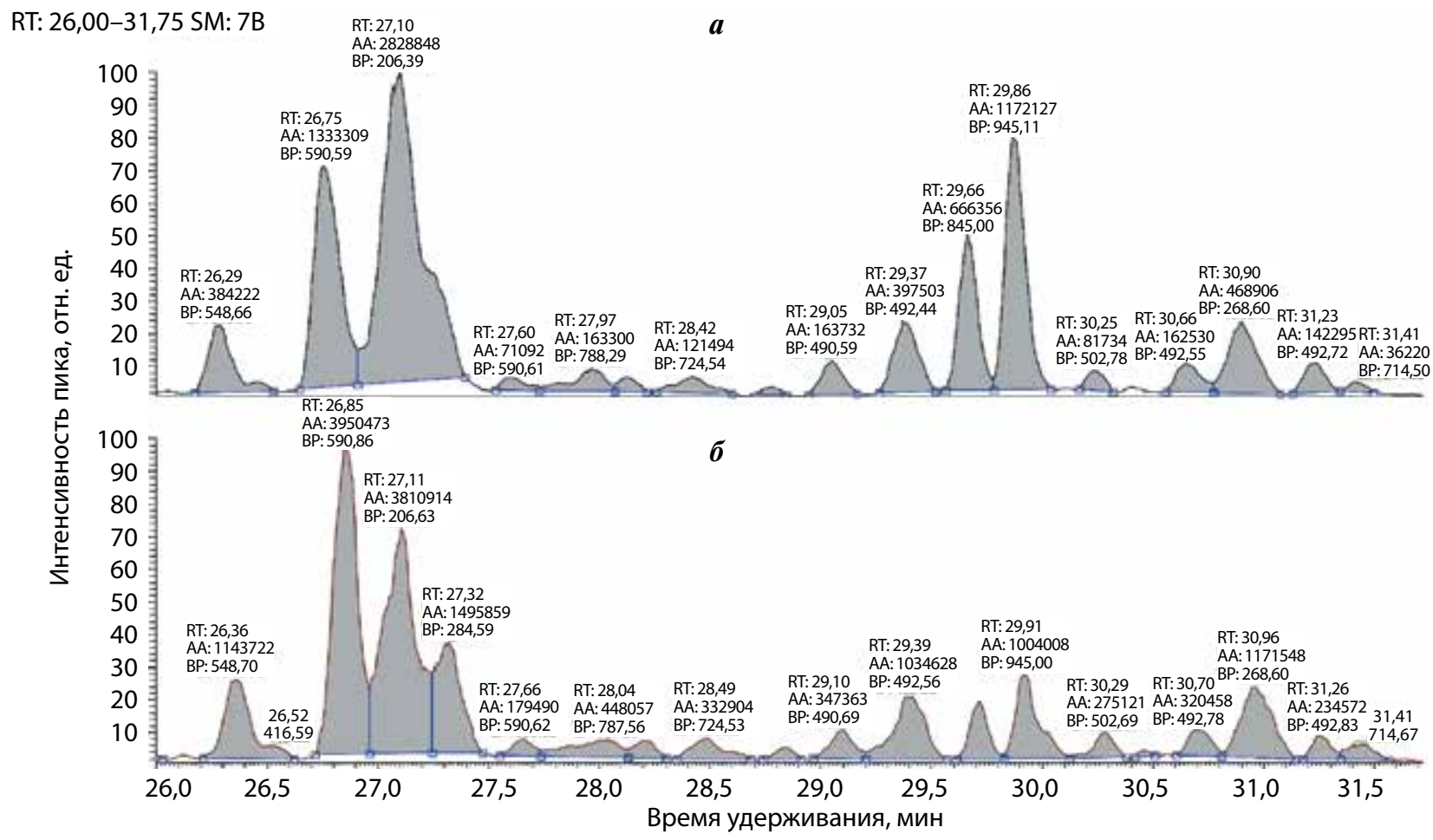

Рис. 6. Отрезки хроматограмм препаратов «Фитомикс-40» (а) и сравнения (б) во временно́м интервале 26-31,75 мин (присутствуют пики гинзенозидов $\operatorname{Re}$ и $R g_{1}$ ) 
Таблица 5. Результаты тандемной масс-спектрометрии (номера пиков соответствуют данным, представленным на рис. 2)

\begin{tabular}{|c|c|c|c|}
\hline $\begin{array}{c}\text { № } \\
\text { пика }\end{array}$ & - & ММ, г/моль & Данные МС, m/z \\
\hline 1 & $\begin{array}{l}\mathrm{Re} \\
\mathrm{C}_{48} \mathrm{H}_{82} \mathrm{O}_{18}\end{array}$ & 947,15 & 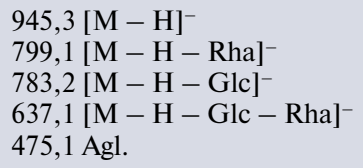 \\
\hline 2 & $\begin{array}{l}\mathrm{Rf} \\
\mathrm{C}_{42} \mathrm{H}_{72} \mathrm{O}_{14}\end{array}$ & 801,01 & $\begin{array}{l}845,5[\mathrm{M}+\mathrm{FA}-\mathrm{H}]^{-} \\
799,5[\mathrm{M}-\mathrm{H}]^{-} \\
637,5[\mathrm{M}-\mathrm{H}-\mathrm{Glc}]^{-} \\
\text {475,3 Agl. }\end{array}$ \\
\hline 4 & $\begin{array}{l}\mathrm{Rg}_{2} \\
\mathrm{C}_{42} \mathrm{H}_{2} \mathrm{O}_{13}\end{array}$ & 785,01 & $\begin{array}{l}\text { 783,2 [M - H }]^{-} \\
636,8\left[\mathrm{M}-\mathrm{H}-\mathrm{Rha}^{-}\right. \\
621,1[\mathrm{M}-\mathrm{H}-\mathrm{Glc}]^{-} \\
\text {475,1 Agl. }\end{array}$ \\
\hline 7 & $\begin{array}{l}\text { Ro } \\
\mathrm{C}_{48} \mathrm{H}_{76} \mathrm{O}_{19}\end{array}$ & 957,1 & $\begin{array}{l}955,3[\mathrm{M}-\mathrm{H}]^{-} \\
793,1[\mathrm{M}-\mathrm{H}-\mathrm{Glc}]^{-} \\
631,1[\mathrm{M}-\mathrm{H}-2 \mathrm{Glc}]^{-} \\
613,2\left[\mathrm{M}-\mathrm{H}-2 \mathrm{Glc}-\mathrm{H}_{2} \mathrm{O}\right]^{-}\end{array}$ \\
\hline
\end{tabular}

Примечание: $M M$ - молекулярная масса, $M C$ - масс-спектрометрический анализ, FA - муравьиная кислота, Glc - глюкоза, Agl. агликон, FA - муравьиная кислота, $m$ - масса иона; $z$ - заряд иона, Rha - рамноза. данных видно, что количество гинзенозидов $\mathrm{Re}, \mathrm{Rf}$ и $\mathrm{Rg}_{2}$ в препарате ФМ-40 превышает таковое в ПС в 3,06, 3,82 и 2,95 раза соответственно. В препарате ФМ-40 гинзенозидов Ro, малонил- $\mathrm{Rb}_{1},-\mathrm{Rb}_{2} / \mathrm{Rb}_{3} / \mathrm{Rc}$ и - $\mathrm{Rd}$ содержится соответственно в 2,94, 2,68, 2,9 и 3,47 раз больше, чем в ПС.

Таким образом, установлено, что в составе препарата ФМ-40 в сравнении с ПС присутствует в среднем в 3 раза больше всех идентифицированных (с использованием стандартов и по литературным данным) соединений женьшеня. Полученные результаты согласуются с различиями в составе фитокомпозиций (экстрактов растений-адаптогенов в ФМ-40 в 3 раза больше, чем в ПС) и тем самым подтверждают корректность данных исследований.

\section{Выводы}

В настоящих исследованиях установлены оптимальные условия разделения гинзенозидов на обращенно-фазовой колонке ACQUITY UPLC BEH C18 с использованием градиентного изократического элюирования. Оптимизированы условия работы источника ионизации пробы электрораспылением. Получен-
RT: 39,72-44,92 SM: 7B

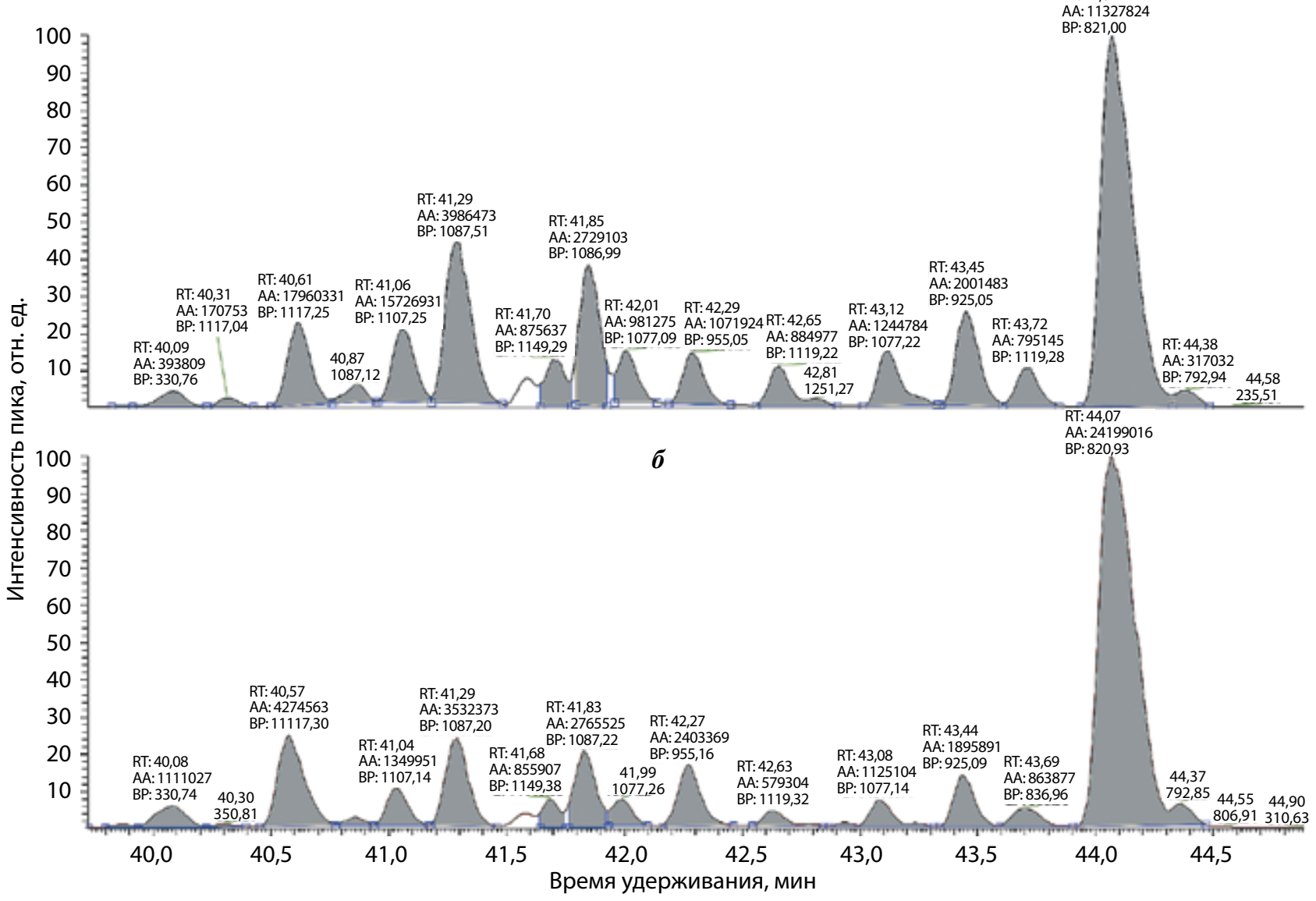

Рис. 7. Отрезки хроматограмм препаратов «Фитомикс-40» (а) и сравнения (б) во временно́м интервале 39,72-44,92 мин (присутствуют пики гинзенозидов $R b_{1}, R c, R o, R b_{2}$ ) 
Таблица 6. Площади пиков гинзенозидов и их соотношение между препаратами ФМ-40, ПС (данные соответствуют хроматограммам, представленным на рис. 6 и 7)

\begin{tabular}{|c|c|c|c|c|c|}
\hline \multirow{2}{*}{ Гинзенозид } & \multirow{2}{*}{$\mathbf{R}_{t}$, мин } & \multicolumn{2}{|c|}{$\begin{array}{c}\text { Площадь соответствующего пика } \\
\text { на хроматограмме, ед. площади }\end{array}$} & \multicolumn{2}{|r|}{ Коэффициент соотношения веществ } \\
\hline & & ФМ-40 & ПС & ФМ-40 и ПС & ФМ-40 и ПС с учетом поправочного множителя \\
\hline $\operatorname{Rg}_{1}$ & 29,7 & 666356 & 601349 & 1,11 & 2,91 \\
\hline $\mathrm{Rb}_{1}$ & 41,1 & 1572693 & 1349951 & 1,16 & 3,05 \\
\hline $\mathrm{Rc}$ & 42,0 & 981275 & 856113 & 1,14 & 2,99 \\
\hline $\mathrm{Rb}_{2}$ & 43,1 & 1244784 & 1125104 & 1,11 & 2,90 \\
\hline $\mathrm{Rd}$ & 45,2 & 561062 & 466446 & 1,20 & 3,15 \\
\hline
\end{tabular}

Примечание: $R_{t}$ - время удерживания, ФМ-40 - фитомикс-40, ПС - препарат сравнения.

Таблица 7. Площади пиков гинзенозидов, идентифицированных на основании литературных данных, а также их соотношение между препаратами ФМ-40 и ПС (данные соответствуют хроматограммам, представленным на рис. 6 и 7)

\begin{tabular}{|c|c|c|c|c|c|}
\hline \multirow{2}{*}{ Гинзенозид } & \multirow{2}{*}{$\mathbf{R}_{\mathbf{t}}$, мин } & \multicolumn{2}{|c|}{$\begin{array}{c}\text { Площадь соответствующего пика } \\
\text { на хроматограмме, ед. площади }\end{array}$} & \multicolumn{2}{|r|}{ Коэффициент соотношения веществ } \\
\hline & & ФМ-40 & ПС & ФМ-40 и ПС & ФМ-40 и ПС с учетом поправочного множителя \\
\hline $\operatorname{Re}$ & 29,9 & 1172127 & 1004008 & 1,17 & 3,06 \\
\hline $\mathrm{Rf}$ & 36,8 & 276190 & 189237 & 1,46 & 3,82 \\
\hline $\operatorname{Rg}_{2}$ & 39,4 & 143357 & 127381 & 1,13 & 2,95 \\
\hline Ro & 42,3 & 1071924 & 953369 & 1,12 & 2,94 \\
\hline Малонил- $\mathrm{Rb}_{1}$ & 41,7 & 875637 & 855907 & 1,02 & 2,68 \\
\hline Малонил- $\mathrm{Rb}_{2} / \mathrm{Rb}_{3} / \mathrm{Rc}$ & 42,6 & 654107 & 578934 & 1,13 & 2,96 \\
\hline Малонил- $\mathrm{Rb}_{2} / \mathrm{Rb}_{3} / \mathrm{Rc}$ & 43,7 & 795145 & 712569 & 1,12 & 2,92 \\
\hline Малонил-Rd & 45,8 & 435126 & 327972 & 1,33 & 3,47 \\
\hline
\end{tabular}

Примечание: ФМ-40 - фитомикс-40, ПС - препарат сравнения, $R_{t}$ - время удерживания.

ные в ходе данной работы хроматограммы и спектры компонентов препарата могут быть использованы в качестве стандартов гинзенозидов. ВЭЖХ-МС/МС с использованием стандартов гинзенозидов и данных литературы была успешно применена для идентификации и количественного определения гинзенозидов
$\mathrm{Rb}_{1}, \mathrm{Rb}_{2}, \mathrm{Rc}, \mathrm{Rd}, \mathrm{Rg}_{1}, \mathrm{Rg}_{2}, \mathrm{Re}, \mathrm{Rf}, \mathrm{Ro}$, малонил- $\mathrm{Rb}_{1}$, $-\mathrm{Rb}_{2} / \mathrm{Rb}$ / $/ \mathrm{Rc}$ и - $\mathrm{Rd}$ в качестве составляющих мультифитоадаптогена на примере ФМ-40. В результате определены подходы к стандартизации фитопрепаратов, в состав которых входят биологически активные вещества женьшеня, в том числе гинзенозиды.

\section{Л И Т E P A T}

1. Бочарова О.А., Барышников А.Ю., Давыдов М.И. Фитоадаптогены в онкологии и геронтологии. М.: МИА. 2008. 2. Бочарова О.А., Давыдов М.И., Барышников А.Ю. и др. Комплексные фитоадаптогены в онкологии и геронтологии. Вестник РАМН 2009;8:21-5.
3. Бочаров Е.В., Кучеряну В.Г., Крыжановский Г.Н. и др. Влияние комплексного фитоадаптогена на МФТП-индуцированный паркинсонический синдром у мышей. Бюллетень экспериментальной биологии и медицины 2006;141(5):495-8.
4. Бочаров Е.В., Кучеряну В.Г., Бочарова О.А., Карпова Р.В. Нейропротекторные свойства фитоадаптогенов. Вестник РАМН 2008;4:47-50.

5. Бочаров Е.В., Карпова Р.В., Казеев И.В. и др. Исследование радиозащитной активности мультифитоадаптогена 
в эксперименте на мышах. Патологическая физиология и экспериментальная терапия 2013;3:55-8.

6. Бочарова О.А., Карпова Р.В., Голубева В.А. и др. Токсикологическое изучение препарата Фитомикс-40. Гигиена и санитария 1999;5:60-1.

7. Бочарова О.А., Чекалина Т.Л., Мезенцева М.В. и др. Перспективы использования Фитомикс-40 для профилактической онкологии. Российский биотерапевтический журнал 2002;1(2):114. 8. Бочарова О.А., Лыженкова М.А., Мезенцева М.В. и др. Фитоадаптоген для профилактической онкологии: иммунобиологические критерии состава. Бюллетень экспериментальной биологии и медицины 2003;136(12):670-3.

9. Бочарова О.А., Карпова Р.В.,

Ильенко В.А. и др. Лейкоцитарные интегрины при гепатоканцерогенезе мышей высокораковой линии СВА. Российский биотерапевтический журнал.

2013;12(3):53-6.

10. Карпова Р.В., Бочаров Е.В.,

Казеев И.В. и др. Радиозащитная эффективность мультифитоадаптогена в опытах на собаках. Патологическая физиология и экспериментальная терапия. 2013;4:51-4. 11. Куренная О.Н., Карпова Р.В., Бочарова О.А. и др. Антимутагенез мультифитоадаптогена в клетках дрожжейсахаромицетов. Генетика. 2013; 49(12):1364-9.

12. Bocharova O.A., Kucheryanu V.G., Kryzhanovsky G.N. et al. Phytomix-40: antiparkinsonian and antioxidant activities. Abstracts of 2nd World Meeting on Pharmaceutics, Biopharmaceutics and Pharmaceutical Technology 1998:1161-2.

13. Бочаров Е.В., Иванова-Смоленская И.А. Полешук В.В. и др. Возможности фитоадаптогена-нейропротектора при лечении нейродегенеративного заболевания (на примере болезни Паркинсона). Бюллетень экспериментальной биологии и медицины 2010;149(6):619-21.

14. Бочарова О.А., Пожарицкая М.М., Чекалина Т.Л., Воронин В.Ф. Современные аспекты патогенеза и лечения лейкоплакии слизистой оболочки полости рта. Методическое руководство для врачей. М.: ВУНМЦ, 2004.

15. Бочарова О.А., Пожарицкая М.М., Чекалина Т.Л. и др. Лейкоплакия слизистой оболочки полости рта: патогенез и возможности коррекции фитоадаптогеном. Бюллетень экспериментальной биологии и медицины 2004;138(12):652-7.

16. Бочарова О.А., Матвеев В.Б.,

Карпова Р.В. и др. Коррекция клиниче- ских и иммунобиологических показателей у мужчин с доброкачественной гиперплазией предстательной железы фитоадаптогеном. Бюллетень экспериментальной биологии и медицины 2006;141(5):555-9.

17. Бочарова О.А., Давыдов М.И., Клименков А.А. и др. Перспективы применения фитоадаптогена в лечении распространенного рака желудка. Бюллетень экспериментальной биологии и медицины 2009;148(7):96-9.

18. Бочков Н.П., Бочарова О.А.,

Аксенов А.А. и др. Частота хромосомных аберраций в лимфоцитах пациентов с доброкачественной гиперплазией предстательной железы. Медицинская генетика 2005;4(1):15-9.

19. Багирова В.Л., Северцев В.А.

Настойки, экстракты и их стандартизация. СПб: СпецЛит, 2001.

20. Бочарова О.А., Куренная О.Н., Серебрякова Р.В., Бодрова Н.Б. Новый способ биологического тестирования препаратов адаптогенов. Биотехнология 1993(8):28-34.

21. Бочарова О.А., Лыженкова М.А., Куренная О.Н., Княжев В.А. Способ биологического контроля комплексного фитоадаптогена. Бюллетень экспериментальной биологии и медицины 2003;136(12):694-9.

22. Бочарова О.А., Барышников А.Ю. Фитоадаптогены в онкологии.

М.: ЗооМедВет, 2004.

23. Зенкевич И.Г., Багирова В.Л., Сокольская Т.А., Нечаева Е.Б. Обзор физико-химических методов стандартизации настоек, экстрактов и эликсиров в ведущих странах Европы и Америки. Фармация 2002;1:43-5.

24. Бочарова О.А. Композиция ингредиентов для препарата Фитомикс-40.

Патент РФ № 2099410, 1998.

25. Шейченко В.И., Бочарова О.А., Шейченко О.П. и др. Аналитические возможности метода ЯМР для определения компонентов препарата Фитомикс-40. Заводская лаборатория. Диагностика материалов 2006;2(8):15-23.

26. Шейченко О.П., Бочарова О.А., Крапивкин Б.А. и др. Определение химического состава летучих соединений фитоадаптогена «Фитомикс-40» методом хроматомасс-спектрометрии. Вопросы биологической, медицинской и фармацевтической химии 2008;5:18-28. 27. Шейченко О.П., Бочарова О.А., Крапивкин Б.А. и др. Исследование комплексного фитоадаптогена методом ВЭЖХ. Вопросы биологической, меди- цинской и фармацевтической химии 2012;10:52-9.

28. Li H., Lee J.H., Ha J.M. Effective purification of ginsenosides from cultured wild ginseng roots, red ginseng and white ginseng with macroporous resins. J Microbiol Biotechnol 2008;18(11):1789-91. PMID: 19047822

29. Liu Z., Li Y., Li X. et al. The effects of dynamic changes of malonyl ginsenosides on evaluation and quality control of Panax ginseng C.A. Meyer. J Pharm Biomed Anal 2012;64-65:56-63. doi: 10.1016/j. jpba. 2012.02.005. Epub 2012 Feb 15. PMID: 22387101

30. Morinaga O., Uto T., Yuan C.S. et al. Evaluation of a new eastern blotting technique for the analysis of ginsenoside $\mathrm{Re}$ in American ginseng berry pulp extracts. Fitoterapia 2010;81(4):284-8. doi: 10.1016/j. fitote. 2009.10.005. Epub 2009 Oct 20. PMID: 19850112

31. Wong V.K., Cheung S.S., Li T. et al. Asian ginseng extract inhibits in vitro and in vivo growth of mouse lewis lung carcinoma via modulation of ERK-p53 and NF- $\mathrm{KB}$ signaling. J Cell Biochem 2010;111(4):899910. doi: $10.1002 /$ jcb. 22778. PMID: 20665661

32. Chen G., Yang M., Song Y. et al. Comparative analysis on microbial and rat metabolism of ginsenoside $\mathrm{Rb} 1$ by high-performance liquid chromatography coupled with tandem mass spectrometry.

Biomed. Chromatogr. 2008;22(7):779-85. doi: 10.1002/bmc. 1001 .

PMID:18384066

33. Deng G.F., Wang D.L., Meng M.X. et al. Simultaneous determination

of notoginsenoside $\mathrm{R} 1$, ginsenoside $\mathrm{Rg} 1$, Re, $\mathrm{Rb} 1$ and icariin in rat plasma by ultraperformance liquid chromatography-tandem mass spectrometry. J Chromatogr B Analyt Technol Biomed 2009;877(22):2113-22. doi: 10.1016/j. jchromb. 2009.06.003. Epub 2009 Jun 10. PMID: 19541552

34. Li X., Tang M.H., Zhang F. et al. Quantitative determination of ginsenoside Re and $\operatorname{Rg} 1$ in human plasma by ultra performance liquid chromatography-tandem mass spectrometry. Sichuan Da Xue Xue Bao Yi Xue Ban 2009;40(5):912-7. PMID: 19950613

35. Zhao Q., Zheng X., Jiang J. et al.

Determination of ginsenoside $\operatorname{Rg} 3$ in human plasma and urine by high performance liquid chromatography-tandem mass spectrometry. J Chromatogr B Analyt Technol Biomed Life Sci 2010;878(24):2266-73. doi: 10.1016/ j. jchromb. 2010.06.019. Epub 2010 Jun 25. PMID: 20673651 